\title{
Early programming of adult blood pressure in the low birth weight Yucatan miniature pig is exacerbated by a post-weaning high-salt-fat-sugar diet
}

\author{
Semone B. Myrie ${ }^{1}$, Dylan S. MacKay ${ }^{1}$, Bruce N. Van Vliet ${ }^{2}$ and Robert F. Bertolo ${ }^{1 *}$ \\ ${ }^{1}$ Department of Biochemistry, Memorial University of Newfoundland, St John's, Newfoundland and Labrador, \\ Canada $A 1 B 3 \times 9$ \\ ${ }^{2}$ Division of BioMedical Sciences, Memorial University of Newfoundland, St John's, Newfoundland and Labrador, \\ Canada $A 1 B 3 V 6$ \\ (Submitted 13 June 2011 - Final revision received 26 October 2011 - Accepted 7 November 2011 - First published online 16 December 2011)
}

\begin{abstract}
We previously demonstrated that intra-uterine growth-restricted (IUGR) Yucatan miniature pigs develop modestly elevated blood pressure (BP) as young adults. The present study evaluated the effects of a post-weaning Western-style, high-salt-fat-sugar (HSFS) diet on early programming of BP. IUGR piglets (3 d old, 0.77 (SEM 0.04) kg, $n$ 6) were paired with normal weight (NW) same-sex littermates (1.14 (SEM $0.03) \mathrm{kg}, n$ 6) and fed milk replacer for 4 weeks. A third littermate was left with the sow (SF; 1.01 (SEM 0.05) kg, $n$ 6). When 4 weeks old, all pigs were placed on a HSFS diet ad libitum for $5 \mathrm{~h} / \mathrm{d}$. When 11 months old, telemeters were implanted to measure BP in pigs before $(4.5 \% \mathrm{NaCl})$ and after $(0.5 \% \mathrm{NaCl})$ a $7 \mathrm{~d}$ reduced salt challenge. At necropsy, nephron numbers were determined. Before sexual maturity, IUGR pigs had greater relative feed intake $(P<0.05)$, and experienced catch-up growth with greater adiposity, with correlations between adiposity and BP $(P<0 \cdot 05)$. Adult IUGR pigs had 26-34\% fewer nephrons and higher diastolic BP (107.7 (SEM 4.9) mmHg, $P=0.044)$ than NW $(97.2$ (SEM 1.8) $\mathrm{mmHg}$ ) and SF $(98.9$ (SEM 5.3) $\mathrm{mmHg}$ ) pigs. Systolic BP was similar among the three groups, but was significantly elevated compared with levels previously reported for a control diet. Salt restriction reduced BP in all groups $(P<0 \cdot 05)$, but with no differences $(P>0.05)$ in the degree of salt sensitivity among groups. In conclusion, a post-weaning Western-style diet exacerbates early programming of diastolic BP in Yucatan miniature swine, whereas systolic BP is more sensitive to postnatal diet.
\end{abstract}

Key words: Breast-feeding: Catch-up growth: Intra-uterine growth restriction: Western-style diet: Salt sensitivity

Epidemiological and experimental evidence suggests that postnatal diet can amplify detrimental fetal/early programming effects, increasing the risk for the development of CVD, including hypertension, during adulthood ${ }^{(1-3)}$. First, a poor perinatal environment leads to reduced nephron endowment in the offspring, which may have an impact on blood pressure (BP) later in life ${ }^{(4,5)}$. Further, postnatal dietary factors can accelerate the manifestations of hypertension ${ }^{(1,3,6)}$. Recently, several studies have suggested that dietary salt intake is important for the development of hypertension in those with congenitally reduced nephron endowment ${ }^{(1,6-9)}$. Conversely, there are a few studies that failed to note any association between fetal/early programming and salt sensitivity $^{(10-12)}$. In a previous study ${ }^{(12)}$, we reported significant $(P<0 \cdot 05)$, but modest increases in BP values in the naturally occurring spontaneous intra-uterine growth-restricted (IUGR) (i.e. runt) Yucatan miniature pigs in comparison to their larger littermates. In that study, we found that BP in the low birth weight Yucatan miniature pig was negatively associated
$(P<0.05)$ with nephron endowment ${ }^{(12)}$. Impaired nephrogenesis as a result of fetal growth restriction is believed to result in a deficit in the kidney's ability to excrete dietary Na, thus contributing to the development of hypertension, CVD and renal disease $^{(4,5,13)}$. However, in our previous study ${ }^{(12)}$, despite the approximately $40 \%$ reduced nephron endowment in the IUGR Yucatan miniature pigs, a $7 \mathrm{~d}$ acute high salt (4.5\% $\mathrm{NaCl}$ ) challenge revealed no difference in the degree of salt sensitivity between low and larger birth weight pigs. Alternatively, others ${ }^{(1)}$ have suggested that chronic salt loading may be necessary to illustrate the detrimental effects of salt and nephron endowment on BP. Indeed, research has shown that lifestyle factors, including postnatal nutrition, may influence the delay or hasten the onset of chronic disease outcomes in low birth weight offspring ${ }^{(3,14,15)}$. Given the noticeably reduced nephron endowment in the IUGR Yucatan miniature pigs and its association with $\mathrm{BP}$ values in these animals, it is possible that long-term salt loading may exacerbate BP outcomes.

Abbreviations: BP, blood pressure; DAP, diastolic arterial pressure; HSFS, high-salt-fat-sugar; IUGR, intra-uterine growth-restricted; MAP, mean arterial pressure; NW, normal weight; SAP, systolic arterial pressure; SF, sow-fed control pigs.

* Corresponding author: Dr R. F. Bertolo, fax +1 709864 2422, email rbertolo@mun.ca 
Although the role of individual dietary components has been the focus of considerable research, given the complexity of human diets, recent epidemiological research has given greater attention to dietary pattern in the development of $\mathrm{CVD}^{(16,17)}$. For instance, the underlying cause of primary hypertension is multifactorial, including many dietary factors such as excessive consumption of $\mathrm{Na}$, saturated fat and/or simple carbohydrates (sugar) ${ }^{(18)}$, all prominent components of a Western-style diet, which has been estimated to account for over 30\% of the world's CVD events ${ }^{(19)}$. Individually, $\mathrm{Na}$, saturated fat and refined carbohydrates have been shown to contribute to elevated $\mathrm{BP}^{(18)}$, and their individual effects may be additive. The present study was designed to evaluate the overall effects of a poor post-weaning diet on the fetal origins of the later development of CVD. Because the intra-uterine environment programmes the risk for later disease, we hypothesised that long-term exposure to an 'energy-rich, nutrient-poor' Western-style diet that was high in salt, as well as saturated fat and sugar would exacerbate BP outcomes in our recently developed IUGR Yucatan miniature pig model ${ }^{(12)}$.

\section{Materials and methods}

\section{Animals and study protocol}

All animal procedures were approved by the Memorial University of Newfoundland Animal Care Committee in accordance with the Canadian Council on Animal Care Guidelines. Yucatan miniature pigs from six sows from the University's swineherd were studied (average litter size was 8.0 (SEM 0.3) piglets). Within each litter, a runt (i.e. IUGR) piglet (618-869 g), defined as weighing approximately $65 \%$ of the birth weight of the largest littermate ${ }^{(20)}$, was sex-matched to a larger (i.e. normal weight $(\mathrm{NW})$ ) littermate (1057-1251g). After allowing for colostrum consumption, each IUGR-NW piglet pair was removed from the sow when $3 \mathrm{~d}$ old and housed together, but individually provided ad libitum with rehydrated sow milk replacer (Grober Nutrition, Inc.) eight to ten times daily, with all intakes recorded. To avoid normal competition among suckling piglets, IUGR-NW piglet pairs were weaned early onto formula to allow individual pigs to eat to appetite. A third same-sex, sow-fed control (SF) littermate, closest in weight to the NW piglet (856-1182 g), was left with the sow until weaning when 4 weeks old. All pigs were weaned onto a Western-style high-salt-fat-sugar (HSFS) diet when 4 weeks old, and siblings (IUGR, NW and SF) remained group-housed throughout the study. To quantify individual pig daily feed intake, each pig was fed separately for $5 \mathrm{~h} / \mathrm{d}(12.00-17.00$ hours) during which time the diet was freely available and intakes were recorded. This HSFS diet (Table 1) was made by the addition of table salt ( $40 \mathrm{~g} / \mathrm{kg}$; Windsor Company), hydrogenated margarine (50 g/kg; Central Dairies), lard (150 g/kg; Loblaw, Inc.) and granulated sugar ( $100 \mathrm{~g} / \mathrm{kg}$; Lantic) to a standard grower pig diet (Eastern Farmers' Cooperative Society); this formulation provided $50 \%$ of energy intake from fat, $40 \%$ from carbohydrate and $10 \%$ from protein. This Western-style diet was based on the 95th percentile for intake of salt, saturated fat, trans-fat and added sugar in American young adult males
Table 1. Composition of the post-weaning high-salt-fat-sugar (HSFS) diet $^{*}$ fed to the Yucatan miniature pigs

\begin{tabular}{lcc}
\hline & $\begin{array}{c}\text { HSFS diet } \\
\text { (high salt) }\end{array}$ & $\begin{array}{c}\text { HSFS diet } \\
\text { (standard salt) }\end{array}$ \\
\hline Energy distribution (\% total energy) & & \\
Carbohydrates & 40 & 40 \\
$\quad$ Complex & 75 & 75 \\
$\quad$ Sugar & 25 & 25 \\
Fat & 50 & 50 \\
Protein & 10 & 10 \\
Ingredients (g/kg DM) & & \\
Wheat shorts & 264.3 & 264.3 \\
Rapeseed & 32.3 & 32.3 \\
Meat meal & 12.5 & 12.5 \\
Limestone & 8.58 & 8.58 \\
Maize gluten feed & 26.4 & 26.4 \\
Ground barley & 196.0 & 196.0 \\
Oats & 115.5 & 115.5 \\
Vitamin mix & 0.5 & 0.5 \\
Mineral mix & 0.7 & 0.7 \\
Lard & 150.0 & 150.0 \\
Margarine & 50.0 & 50.0 \\
Salt & 40.0 & 4.7 \\
Sugar & 100.0 & 100.0 \\
\hline
\end{tabular}

*HSFS diet was made by the addition of lard $(150 \mathrm{~g} / \mathrm{kg}$; Loblaw, Inc.), hydrogenated margarine $(50 \mathrm{~g} / \mathrm{kg}$; Central Dairies), salt (40 g/kg; Windsor Company) and granulated sugar $(100 \mathrm{~g} / \mathrm{kg}$; Lantic) to ground pig grower diet (Eastern Farmers' Cooperative Society).

$(20-39 \text { years old })^{(21,22)}$. The mineral and vitamin contents were adequate for the predicted growth rate, given the diluted protein concentration of this $\operatorname{diet}^{(23)}$. All animals had $24 \mathrm{~h}$ ad libitum water access and were maintained on a $12 \mathrm{~h}$ day-12 h night cycle (lights on 07.00-19.00 hours). Body weight, crown to rump length and abdominal circumference were measured at least twice weekly before weaning and twice monthly thereafter.

\section{Biochemical analyses}

Monthly blood samples were collected in EDTA tubes, by jugular venepuncture with pigs supine in a V-trough, and plasma stored at $-20^{\circ} \mathrm{C}$ until later analysis for creatinine concentrations using enzymatic assays (Bioassay Systems).

\section{Radiotelemetric measurement of haemodynamics}

When 11 months old, at an average body weight of 62 (SEM 3) $\mathrm{kg}$, the pigs underwent surgery for implantation of an arterial BP telemeter (TA11PA-D70; Data Sciences International) and blood sampling catheters. Briefly, anaesthesia was induced with ketamine ( $22 \mathrm{mg} / \mathrm{kg}$ intramuscularly) and xylazine ( $2 \mathrm{mg}$ / $\mathrm{kg}$ intramuscularly) and maintained with $1.0-1.5 \%$ halothane and 3:2 oxygen-nitrous oxide mixture. The BP telemeter body was implanted subcutaneously in the inner hindlimb, with the telemeter catheter inserted $10 \mathrm{~cm}$ into the left femoral artery. This investigation was part of a larger series of studies; therefore, two blood sampling catheters (inner diameter $1.0 \mathrm{~mm}$, outer diameter $1.8 \mathrm{~mm}$; Tygon ${ }^{\circledR}$ ) were inserted in the left femoral vein, tunnelled under the skin and exteriorised between the shoulder blades. Pigs were given $0.07 \mathrm{ml} / \mathrm{kg}$ intravenously trimethoprim $(40 \mathrm{mg} / \mathrm{ml}) /$ sulfadoxine $(20 \mathrm{mg} / \mathrm{ml})$ 
(Borgal, Intervet Limited) during the first $2 \mathrm{~d}$ post-surgery and $300 \mu \mathrm{g}$ buprenorphrine hydrochloride (Temgesic; ScheringPlough Limited) immediately after surgery and $1 \mathrm{~d}$ post-surgery. After surgery, each animal was housed individually.

The telemetry system (Data Sciences International) was set up to monitor haemodynamics and spontaneous locomotor activity in the pigs, as previously described ${ }^{(12)}$. Individual haemodynamic and activity data were exported from the data acquisition software and transferred to a Microsoft Excel $2000^{\circledR}$ spreadsheet template for data inspection and analysis. Pigs were allowed at least $8 \mathrm{~d}$ recovery from surgery followed by at least $48 \mathrm{~h}$ of continuous BP recordings while on the HSFS $(4.5 \% \mathrm{NaCl})$ diet. Systolic arterial pressure (SAP), diastolic arterial pressure (DAP), mean arterial pressure (MAP), pulse pressure, heart rate and locomotor activity were recorded in each animal. After the $48 \mathrm{~h}$ baseline BP recordings, the pigs were given a standard salt $(0.5 \% \mathrm{NaCl})$ version of HSFS for $7 \mathrm{~d}$, with continuous $\mathrm{BP}$ recordings for the last $48 \mathrm{~h}$ on this diet. At the end of the salt challenge, the diet was reverted to the regular HSFS diet $(4.5 \% \mathrm{NaCl})$ until necropsy.

\section{Necropsy and histology}

Approximately $5 \mathrm{~d}$ after the salt challenge, the pigs were anaesthetised with $105 \mathrm{mg} / \mathrm{kg}$ sodium pentobarbital (Euthanyl; Biomeda-MTC), ventilated and maintained with $0.5-1 \%$ halothane with oxygen. Back-fat thickness was measured on the carcass at the midline of the back, caudal to the last rib. Total visceral organs (i.e. intraperitoneal tissues) were frozen at $-20^{\circ} \mathrm{C}$, later homogenised (Hobart $4346 \mathrm{Mixer} /$ Grinder; Hobart Corporation) and analysed for fat content using a chloroform-methanol extraction technique ${ }^{(24)}$. The lipid-containing phase was evaporated to yield the dry weight of lipids expressed as a percentage of the original sample mass. The heart was weighed and dissected into left and right ventricles. The left kidney was removed and immediately perfusion-fixed with $10 \%$ buffered formalin, and then immersion-fixed in more formalin until histology was performed for nephron measurements.

Kidneys were serially sectioned and glomeruli were counted using unbiased stereological procedures ${ }^{(25)}$. The kidney was cut along the frontal plane into two approximately equal halves and one half was randomly chosen and sliced into $5 \mathrm{~mm}$ slices; every 4 th slice (first slice chosen randomly from 1 to 4) was further cut into $5 \mathrm{~mm}$ strips and rotated to cut into small blocks of similar size. For each strip, every 5 th block (chosen randomly from the interval 1 to 5) was paraffin-embedded and sectioned at $20 \mu \mathrm{m}$ thickness. The 24 th and 25th sections of each block were stained with haematoxylin and eosin for stereological counting of glomeruli numbers (Q) using the optical fractionator program (Stereo Investigator version 4.36; MicroBrightField, Inc.). Total nephron numbers per kidney $\left(N_{\text {kid }}\right)$ were estimated using

$$
N_{\mathrm{kid}}=1 /(f 1 \times 5 \times 25) \times\left(P_{\mathrm{s}} / 2 P_{\mathrm{F}}\right) \times Q,
$$

where $f 1$ is the weight of the sampled slices divided by the weight of the whole kidney; 5 is the inverse of the second (block) sampling fraction; 25 is the inverse of the section sampling fraction; $P_{\mathrm{S}} / 2 P_{\mathrm{F}}$ is the fraction of the section area used for glomerular counting ${ }^{(25)}$. The nucleator program (Stereo Investigator, version 4.36; MicroBrightField, Inc.) was used to count glomeruli as well as to estimate the average glomerular surface area and volume. The nucleator probe takes

Table 2. Growth and feed intake parameters of Yucatan miniature pigs studied

(Mean values with their standard errors $(n 6)$ )

\begin{tabular}{|c|c|c|c|c|c|c|c|c|}
\hline \multirow[b]{2}{*}{ Developmental period } & \multirow[b]{2}{*}{ Age } & \multicolumn{2}{|c|}{ IUGR } & \multicolumn{2}{|c|}{ NW } & \multicolumn{2}{|c|}{ SF } & \multirow[b]{2}{*}{$P$} \\
\hline & & Mean & SEM & Mean & SEM & Mean & SEM & \\
\hline \multicolumn{9}{|l|}{ Body weight (kg) } \\
\hline Birth & $0-3 d$ old & $0.77^{\mathrm{a}}$ & 0.04 & $1 \cdot 14^{\mathrm{b}}$ & 0.03 & $1.01^{b}$ & 0.05 & $<0.0001$ \\
\hline Neonate (weaning) & 1 month old & $3 \cdot 87^{a}$ & 0.24 & $5 \cdot 93^{\mathrm{b}}$ & 0.20 & $5 \cdot 82^{\mathrm{b}}$ & 0.30 & 0.0005 \\
\hline Pre-sexual maturity & 4 months old & $15 \cdot 69^{a}$ & 1.34 & $20 \cdot 40^{\mathrm{b}}$ & 0.74 & $21 \cdot 08^{b}$ & 0.92 & 0.005 \\
\hline Sexual maturity & 7 months old & $35.54^{a}$ & 1.87 & $40 \cdot 14^{a, b}$ & 1.60 & $42 \cdot 93^{\mathrm{b}}$ & 1.92 & 0.013 \\
\hline Post-sexual maturity & 12 months old & $61 \cdot 74$ & 4.06 & $68 \cdot 18$ & $6 \cdot 52$ & $72 \cdot 72$ & 4.44 & 0.140 \\
\hline \multicolumn{9}{|c|}{ Fractional growth rate ( $\mathrm{g} / \mathrm{kg}$ body weight per d) } \\
\hline Neonate & Birth to 1 month old & 44.1 & $3 \cdot 2$ & 43.9 & $2 \cdot 6$ & 44.6 & $3 \cdot 1$ & 0.973 \\
\hline Pre-sexual maturity & $1-4$ months old & $16 \cdot 1^{a}$ & 0.9 & $14 \cdot 3^{b}$ & 0.5 & $14 \cdot 5^{\mathrm{b}}$ & 0.8 & 0.021 \\
\hline Sexual maturity & 4-7 months old & $8 \cdot 8$ & 0.4 & $7 \cdot 3$ & 0.5 & $7 \cdot 6$ & 0.3 & 0.061 \\
\hline Post-sexual maturity & $7-12$ months old & $3 \cdot 7$ & 0.1 & $3 \cdot 7$ & $0 \cdot 1$ & 3.8 & 0.1 & 0.524 \\
\hline \multicolumn{9}{|c|}{ Average daily feed intake ( $\mathrm{g} / \mathrm{kg}$ body weight per $\mathrm{d}$ ) } \\
\hline Neonate & Birth to 1 month old & 348.6 & $22 \cdot 6$ & $372 \cdot 3$ & 17.9 & ND & ND & \\
\hline Pre-sexual maturity & $1-4$ months old & $45 \cdot 4^{\mathrm{a}}$ & 1.4 & $40 \cdot 1^{\mathrm{b}}$ & 0.8 & $42 \cdot 5^{a, b}$ & $2 \cdot 6$ & 0.050 \\
\hline Sexual maturity & 4-7 months old & 30.5 & 1.7 & $26 \cdot 5$ & 1.4 & $27 \cdot 0$ & 1.0 & 0.046 \\
\hline Post-sexual maturity & $7-12$ months old & $22 \cdot 4$ & 0.6 & $20 \cdot 6$ & $1 \cdot 7$ & $21 \cdot 6$ & $1 \cdot 8$ & 0.672 \\
\hline \multicolumn{9}{|c|}{ Feed efficiency (body weight gain/feed intake) (g/kg) } \\
\hline Neonate & Birth to 1 month old ${ }^{*}$ & $123 \cdot 6$ & $8 \cdot 7$ & $113 \cdot 1$ & $7 \cdot 1$ & ND & ND & \\
\hline Pre-sexual maturity & $1-4$ months old & 340.5 & $14 \cdot 6$ & 329.6 & $22 \cdot 7$ & 314.2 & 26.9 & 0.528 \\
\hline Sexual maturity & $4-7$ months old & $299 \cdot 1$ & 8.9 & $280 \cdot 1$ & $12 \cdot 7$ & 291.9 & $15 \cdot 0$ & 0.349 \\
\hline Post-sexual maturity & $7-12$ months old & 195.5 & 7.9 & $186 \cdot 4$ & 14.9 & 206.9 & 10.4 & 0.152 \\
\hline
\end{tabular}

IUGR, intra-uterine growth-restricted; NW, normal weight; SF, sow-fed control pigs; ND, not determined.

${ }_{a, b}$ Mean values within a row with unlike superscript letters were significantly different $(P<0.05)$. Significant differences among groups were assessed by repeated-measures ANOVA followed by Tukey's post hoc test.

${ }^{*}$ Feed intake before the pigs were 1 month old was $\mathrm{ml}$ of reconstituted milk replacer for the IUGR and NW pigs. 
unbiased measurements in a focal plane sufficiently narrow to avoid over-projection and uses these two-dimensional isotropically oriented measurements to estimate glomerular size.

\section{Statistical analysis}

All values are expressed as means with their standard errors and $P<0.05$ was considered significant. All statistical analyses were carried out using Prism 4 (GraphPad Software, Inc.). To account for potential sex differences, we analysed the haemodynamic data using two-way repeated-measures ANOVA, where the dependent variables included group, sex and the interaction between the two; however, this analysis indicated no significant sex effects. As a result, all group comparisons were assessed by one-way repeated-measures ANOVA followed by Tukey's post hoc test and the results were reported only as overall (combined male and female) group means. For within-treatment comparisons, statistical comparisons were made by paired $t$ tests. To determine the major factors affecting BP, we also performed multiple linear regression analysis with birth weight, litter, pre-weaning diet and adiposity (subcutaneous and visceral fat) as independent variables (Minitab Software version 15.1; Minitab, Inc.).

\section{Results}

\section{Effects of birth weight on growth and feed intake}

Sexual maturity in Yucatan pigs occurs from the age of 4 to 7 months ${ }^{(26)}$. Therefore, we partitioned the growth data by developmental periods (Table 2). Before sexual maturity, the
IUGR pigs remained significantly smaller than the NW and SF pigs. However, when 7 months old, there were no differences $(P>0.05)$ in body weight between the IUGR and NW pigs; and when 8-12 months old, there were no differences $(P>0.05)$ in body weight among groups, indicating catch-up growth in the IUGR pigs (Table 2). Furthermore, as shown in Table 2 , from 1 to $4(P=0.021)$ and from 4 to 7 $(P=0.061)$ months of age, the fractional growth rates of the IUGR pigs tended to be higher than those of the NW and SF pigs. The higher fractional growth rates of the IUGR pigs appeared to be the result of greater relative feed intake as opposed to improved feed efficiency (Table 2). At the end of the study, when 12 months old, relative back-fat thickness tended to be greater for the IUGR pigs $(0.95$ (SEM 0.05$) \mathrm{mm} /$ kg bodyweight, $P=0.07$ ) compared to the $\mathrm{NW}$ and $\mathrm{SF}$ pigs (0.84 (SEM 0.05) and 0.86 (SEM 0.06$) \mathrm{mm} / \mathrm{kg}$ bodyweight, respectively). However, relative visceral fat content was not different among groups (IUGR: 31.6 (SEM 2.3) \% $v$. NW: 31.6 (SEM 2.1)\% $v$. SF: $29 \cdot 9$ (SEM 5.1)\%, respectively, $P>0 \cdot 05$ ). These data suggest that catch-up growth in the IUGR pigs was probably associated with greater relative feed intake, leading to greater subcutaneous fat deposition.

\section{Haemodynamics and nephron endowment}

As shown in Table 3, on a post-weaning high-salt, high-energy (HSFS) diet, when 12 months old, the IUGR pigs had greater $(P=0 \cdot 044)$ DAP values compared to the NW and SF pigs. However, no differences were observed for SAP or other haemodynamic parameters (Table 3). There were also significant

Table 3. Summary of basic haemodynamic parameters for adult Yucatan miniature pigs fed a post-weaning high-salt-fat-sugar (4.5\% sodium chloride) diet and a lower-salt $(0.5 \%$ sodium chloride) version of the diet

(Mean values with their standard errors $(n 6))$

\begin{tabular}{|c|c|c|c|c|c|c|c|}
\hline \multirow[b]{2}{*}{ Variable } & \multicolumn{2}{|c|}{ IUGR } & \multicolumn{2}{|c|}{ NW } & \multicolumn{2}{|c|}{ SF } & \multirow[b]{2}{*}{$P$} \\
\hline & Mean & SEM & Mean & SEM & Mean & SEM & \\
\hline \multicolumn{8}{|c|}{ Chronic diet for 11 months (HSFS; $4.5 \% \mathrm{NaCl}$ ) } \\
\hline $\mathrm{DAP}(\mathrm{mmHg})$ & $107 \cdot 7^{\mathrm{a}}$ & 4.9 & $97 \cdot 2^{b}$ & $1 \cdot 8$ & $98 \cdot 9^{a, b}$ & $5 \cdot 3$ & 0.044 \\
\hline $\mathrm{SAP}(\mathrm{mmHg})$ & $151 \cdot 3$ & $4 \cdot 1$ & $152 \cdot 1$ & $2 \cdot 6$ & 155.9 & $5 \cdot 6$ & 0.709 \\
\hline MAP (mmHg) & $129 \cdot 1$ & $3 \cdot 6$ & $122 \cdot 8$ & $2 \cdot 0$ & $125 \cdot 4$ & $5 \cdot 3$ & 0.281 \\
\hline $\mathrm{PP}(\mathrm{mmHg})$ & 43.6 & $6 \cdot 1$ & $55 \cdot 0$ & 1.5 & $57 \cdot 0$ & $1 \cdot 7$ & 0.144 \\
\hline HR (beats/min) & 94.7 & 2.5 & $91 \cdot 2$ & $2 \cdot 1$ & $90 \cdot 6$ & $1 \cdot 6$ & 0.194 \\
\hline \multicolumn{8}{|c|}{ Acute diet for $7 d$ (HSFS; $0.5 \% \mathrm{NaCl}$ ) } \\
\hline DAP (mmHg) & $97 \cdot 9$ & 3.9 & $90 \cdot 3$ & $1 \cdot 7$ & 91.6 & $3 \cdot 3$ & 0.107 \\
\hline SAP $(\mathrm{mmHg})$ & $140 \cdot 0$ & $3 \cdot 3$ & $144 \cdot 3$ & $2 \cdot 1$ & $146 \cdot 3$ & $3 \cdot 2$ & 0.380 \\
\hline MAP (mmHg) & $118 \cdot 3$ & $2 \cdot 8$ & $114 \cdot 3$ & $1 \cdot 8$ & $116 \cdot 2$ & $3 \cdot 2$ & 0.317 \\
\hline $\mathrm{PP}(\mathrm{mmHg})$ & $42 \cdot 0$ & $5 \cdot 0$ & $53 \cdot 9$ & 2.5 & $54 \cdot 7$ & $2 \cdot 2$ & 0.128 \\
\hline HR (beats/min) & $91 \cdot 8$ & 1.7 & 84.5 & $2 \cdot 6$ & $88 \cdot 8$ & $3 \cdot 2$ & 0.254 \\
\hline \multicolumn{8}{|c|}{$\begin{array}{l}\text { Difference in haemodynamic values } \\
\text { between the } 4.5 \text { and } 0.5 \% \mathrm{NaCl} \text { di }\end{array}$} \\
\hline $\mathrm{DAP}(\mathrm{mmHg})$ & $9 \cdot 8^{\star \star}$ & 1.5 & $6 \cdot 8^{\star}$ & $2 \cdot 1$ & $7 \cdot 3$ & $3 \cdot 2$ & 0.549 \\
\hline $\mathrm{SAP}(\mathrm{mmHg})$ & $11 \cdot 4^{\star \star *}$ & $1 \cdot 0$ & $7 \cdot 9^{\star}$ & $2 \cdot 7$ & $9 \cdot 6^{*}$ & $3 \cdot 3$ & 0.549 \\
\hline MAP $(\mathrm{mmHg})$ & $10 \cdot 8^{\star \star \star}$ & $1 \cdot 0$ & $8 \cdot 5^{\star}$ & $2 \cdot 6$ & $9 \cdot 1^{*}$ & $3 \cdot 1$ & 0.733 \\
\hline $\mathrm{PP}(\mathrm{mmHg})$ & 1.6 & $1 \cdot 8$ & 1.0 & 1.4 & $2 \cdot 3$ & $1 \cdot 7$ & 0.828 \\
\hline HR (beats/min) & 2.9 & $1 \cdot 3$ & $6 \cdot 7$ & 2.4 & $1 \cdot 8$ & 2.4 & 0.281 \\
\hline
\end{tabular}

IUGR, intra-uterine growth-restricted; NW, normal weight; SF, sow-fed control pigs; HSFS, high-salt-fat-sugar diet; DAP, diastolic arterial pressure; SAP, systolic arterial pressure; MAP, mean arterial pressure; PP, pulse pressure; HR, heart rate.

${ }^{a, b}$ Mean values within a row with unlike superscript letters are significantly different $(P<0.05)$. Significant differences among groups were assessed by one-way repeatedmeasures ANOVA followed by Tukey's post hoc test.

Blood pressure parameter was significantly affected by the salt content of the diet within a group (i.e. parameter compared vertically within a column): $P<0.05$, ${ }^{\star \star} P<0.001$, ${ }^{* * \star} P<0.0001$ (assessed by paired $t$ test). 
correlations between adiposity and BP parameters measured while consuming the HSFS diet (i.e. $4.5 \% \mathrm{NaCl}$ ) (Fig. 1). However, there were no differences in cardiac parameters among groups (Table 4). The multiple linear regression analyses demonstrated that birth weight, litter, pre-weaning diet, visceral fat and subcutaneous fat, all significantly affected BP parameters, i.e. for DAP, $R^{2} 0.66, P=0.013$; SAP, $R^{2} 0.52$, $P=0.082$; MAP, $R^{2} 0.66, P=0.014$. However, the impact of each factor varied depending on the BP parameter. Preweaning diet (12-19\%), litter (17-21\%) and subcutaneous fat $(2-6 \%)$ accounted for a consistent amount of variance for all BP parameters. However, birth weight (26\%) accounted for more of the variance in SAP than visceral fat (7\%) whereas for DAP, visceral fat (15\%) accounted for more variance than birth weight (7\%)
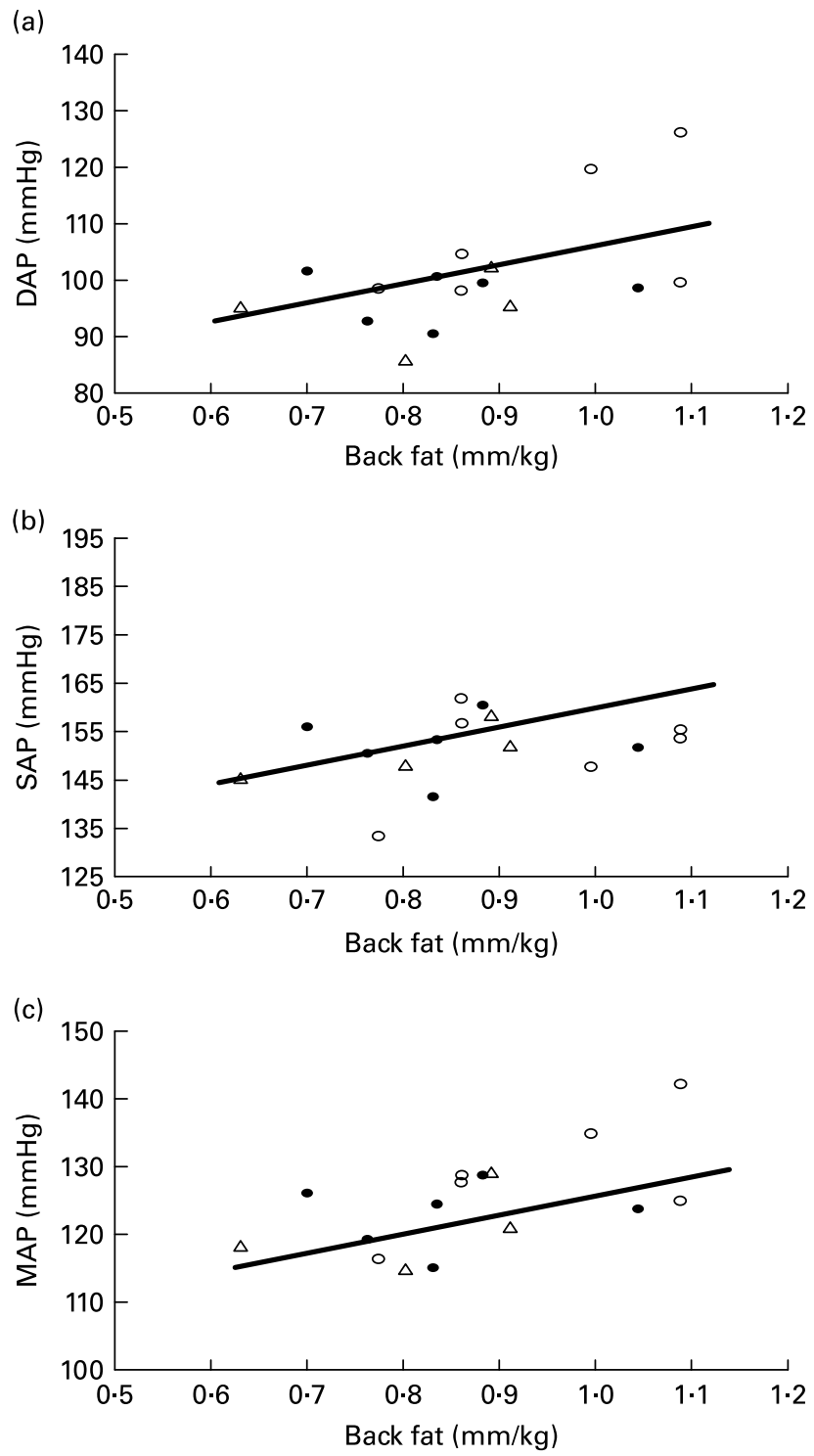

Fig. 1. Effects of adiposity on blood pressure parameters in adult Yucatan miniature pigs fed a high-salt-fat-sugar diet. Column A: Correlation between blood pressure parameters and subcutaneous fat deposition (i.e. back-fat thickness), $n$ 16. (a) $R 0.55, P=0.03$; (b) $R 0.28, P=0.29$; (c) $R 0.60, P=0.01$. Column $\mathrm{B}$ : Correlation between blood pressure parameters and visceral fat deposition, $n$ 18. (d) $R 0.57, P=0.01 ;(\mathrm{e}) R 0.33, P=0.18$; (f) $R 0.55, P=0.02$. IUGR, intra-uterine growth-restricted (O); NW, normal weight $(\bullet)$; SF, sow-fed control pigs $(\triangle)$; DAP, diastolic arterial pressure $(\mathrm{mmHg})$; SAP, systolic arterial pressure $(\mathrm{mmHg})$; MAP, mean arterial pressure $(\mathrm{mmHg})$.
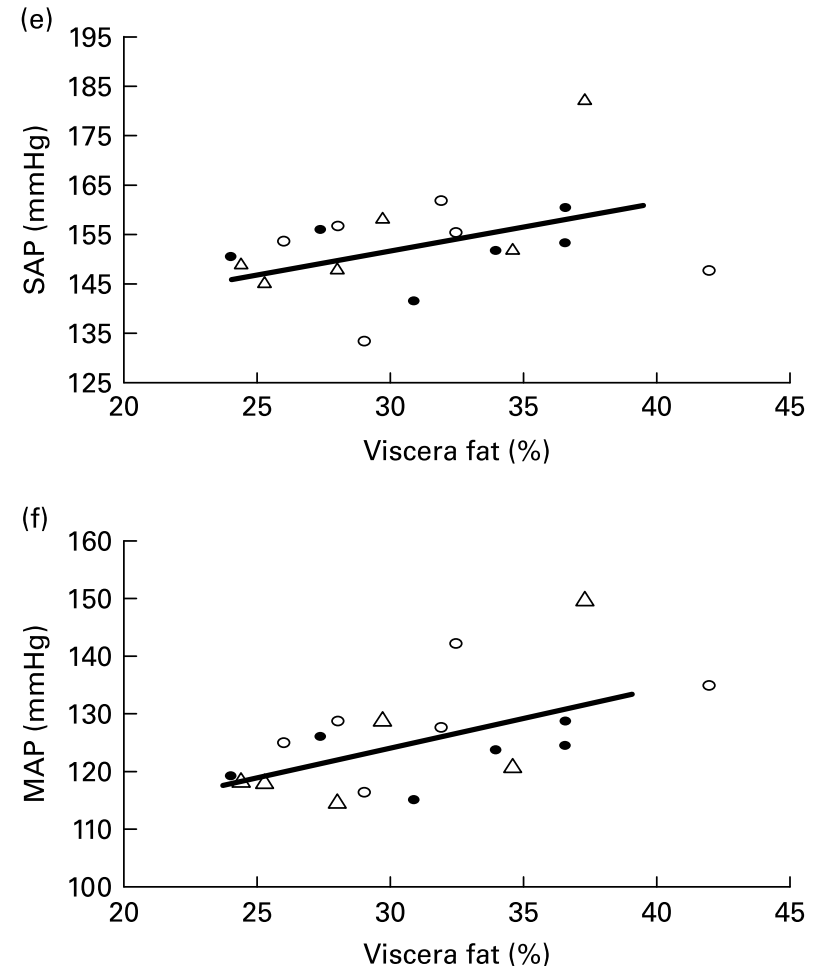
Table 4. Renal and cardiac parameters in adult Yucatan miniature pigs fed a post-weaning high-salt-fat-sugar diet

(Mean values with their standard errors $(n 6)$ )

\begin{tabular}{|c|c|c|c|c|c|c|c|}
\hline & \multicolumn{2}{|c|}{ IUGR } & \multicolumn{2}{|c|}{ NW } & \multicolumn{2}{|c|}{ SF } & \multirow[b]{2}{*}{$P^{*}$} \\
\hline & Mean & SEM & Mean & SEM & Mean & SEM & \\
\hline \multicolumn{8}{|l|}{ Renal parameters } \\
\hline Total kidney wt (kg) & 0.153 & 0.007 & 0.173 & 0.012 & $0 \cdot 186$ & 0.005 & 0.066 \\
\hline Total kidney:body wt ratio (\%) & 0.252 & 0.014 & 0.258 & 0.016 & 0.261 & 0.019 & 0.648 \\
\hline Nephron number per kidney & 250636 & 28109 & 338662 & 18315 & 381259 & 54785 & 0.051 \\
\hline Average glomerular surface area $\left(\mu \mathrm{m}^{2}\right)$ & 23235 & 1323 & 22249 & 894 & 21303 & 1619 & 0.481 \\
\hline Average glomerular volume $\left(\mu \mathrm{m}^{3} \times 10^{6}\right)$ & 2.9 & 0.3 & $2 \cdot 7$ & 0.2 & 2.6 & 0.3 & 0.508 \\
\hline Plasma creatinine $(\mu \mathrm{M})$ & $81 \cdot 6$ & $2 \cdot 9$ & $85 \cdot 3$ & 4.0 & 84.9 & 3.0 & 0.521 \\
\hline \multicolumn{8}{|l|}{ Cardiac parameters } \\
\hline Heart wt $(\mathrm{kg})$ & 0.153 & 0.009 & 0.165 & 0.012 & 0.178 & 0.007 & 0.078 \\
\hline Heart/body wt (\%) & 0.253 & 0.012 & 0.245 & 0.006 & 0.247 & 0.013 & 0.893 \\
\hline Left ventricle $(\mathrm{kg})$ & 0.117 & 0.008 & 0.123 & 0.009 & 0.134 & 0.005 & 0.071 \\
\hline Right ventricle (kg) & 0.036 & 0.006 & 0.042 & 0.003 & 0.044 & 0.002 & 0.364 \\
\hline Right/left ventricle & 0.320 & 0.046 & 0.344 & 0.007 & 0.333 & 0.014 & 0.817 \\
\hline
\end{tabular}

IUGR, intra-uterine growth-restricted; NW, normal weight; SF, sow-fed control pigs.

${ }^{\star}$ Significant differences among dietary treatments were assessed by one-way repeated-measures ANOVA with $P<0.05$ as significant

versions of the HSFS diet, DAP remained more elevated in the IUGR pigs compared to the NW and SF pigs (Table 3). However, the change in BP as a result of the reduced salt challenge showed that the degree of salt sensitivity was not significantly different among groups (Table 3), nor were there significant correlations between the degree of salt sensitivity and birth weight (data not shown).

\section{Discussion}

In the present study, the following findings were made in pigs fed a Western-style HSFS diet: (1) the IUGR pigs experienced catch-up growth accompanied by increased adiposity that was correlated with BP; (2) DAP was increased in the IUGR pigs relative to their larger littermates, and the $\mathrm{BP}$ of all pigs on the HSFS diet was higher than that previously reported for pigs on regular feed; (3) nephron numbers correlated with birth weight and tended $(P=0.051)$ to be reduced in the IUGR pigs; (4) a similar modest degree of acute salt sensitivity of BP was present in each group; (5) suckling did not confer any benefit compared to formula feeding in any parameter.

In a recent study, we found that the IUGR Yucatan miniature pigs fed a healthy, standard grower diet experienced early catch-up growth and developed higher BP by early adulthood $^{(12)}$. The present study was designed to exacerbate the early programming of higher BP by feeding an 'energyrich', 'nutrient-dilute', Western-style diet. Even on this poor diet, the IUGR Yucatan miniature pigs experienced catch-up growth by the age of 7 months, due to greater feed intake rather than enhanced feed efficiency (Table 2). It should be noted that because of the higher energy density of the HSFS diets, total feed intakes were lower than in our previous study which led to lower growth rates (i.e. due to lower protein intake). Nevertheless, similar to our previous study, the IUGR pigs tended to have more subcutaneous fat $(P=0.07)$, suggesting that this early catch-up growth involves greater adiposity. Moreover, both subcutaneous and visceral fat were positively associated with BP parameters (Fig. 1), suggesting that greater adiposity in the IUGR pigs, associated with catch-up growth, may also mediate the increase in BP later in life, similar to studies in rodents ${ }^{(15,27)}$. The mechanism of such an association is complex, but may be mediated by the vasoactive effects of adipokines including adiponectin and $\operatorname{leptin}^{(28)}$.

The increased metabolic demand of obesity can also contribute to glomerular hyperfiltration and hypertrophy, thereby promoting glomerulosclerosis ${ }^{(29,30)}$. This risk becomes substantially greater when compounded with reduced nephron numbers ${ }^{(4,30)}$, as observed in the IUGR pigs. In the present study, the similarity in plasma creatinine concentrations among the groups throughout the study suggested that the overall level of glomerular filtration was normal and that there was probably an increased filtration rate in individual nephrons in the IUGR pigs to compensate for the lower number of glomeruli (i.e. nephrons). However, it should be noted that lower creatine stores in leaner IUGR pigs could confound creatine as a marker of glomerular filtration rate. As there was no significant difference in glomerular size among the groups, any increase in filtration by individual nephrons was presumably due to alterations in glomerular function, rather than adaptive changes in glomerular size. These data, combined with the similar modest degree of salt sensitivity of BP in all groups, suggest that renal function of the IUGR pigs was not severely affected despite the moderate reduction in nephron numbers.

The effects of the chronic HSFS diet itself on BP are evident when data from the present study are compared with our previously reported data for a control diet ${ }^{(12)}$. Relative to that control diet, the post-weaning HSFS ( $4.5 \% \mathrm{NaCl}$ ) diet appeared to raise SAP in the NW pigs (from 134 to $152 \mathrm{mmHg}$ ) to a greater extent than in the IUGR pigs (from 141 to $151 \mathrm{mmHg}$ ), thereby masking the effects of early programming on SAP that we previously observed on the control diet. These data suggest that, in this case, post-weaning nutrition had a greater impact on SAP than fetal/pre-weaning nutrition and development. In contrast, the post-weaning HSFS diet increased DAP more in the IUGR pigs (from 94 to $108 \mathrm{mmHg}$ ) compared to the NW pigs (from 90 to $97 \mathrm{mmHg}$ ), suggesting that the HSFS diet 
exacerbated the fetal/early programming of DAP. Indeed, the early programming of DAP persisted regardless of exposure to either the lower- or the high-salt version of the HSFS diet, unlike SAP (Table 3). Thus, such data suggest that while a poor postnatal diet exacerbates fetally programmed DAP, elevations in SAP from such a diet become disconnected from intra-uterine effects, and SAP levels simply reflect the postnatal diet. Such differential effects of prenatal $v$. postnatal diet environment on systolic and diastolic BP have also been observed in rats, where both SAP and DAP are affected by a fat-rich prenatal diet, whereas only SAP responds to such a diet postnatally, regardless of birth weight ${ }^{(14)}$. Such findings may not be surprising considering that there are different mechanisms regulating systolic and diastolic $\mathrm{BP}^{(31,32)}$.

In addition to the effects on BP parameters, chronic consumption of the HSFS diet also had other metabolic effects not reported here. For instance, this diet significantly increased plasma TAG and total cholesterol concentrations in all pigs; however, the levels among groups were not different and no atherosclerotic plaques were observed. Moreover, this diet had no effect on fasting plasma insulin concentrations and insulin sensitivity, and no differences were observed among groups (data not shown).

The general composition of the average Western-style diet tends to be high not only in fats, but also in sugar and salt. Considering the high fat (saturated and trans-fat) content of our HSFS diet, it is feasible that chronic exposure to high dietary fat, in addition to high dietary salt, could contribute to increased SAP in all of the animals, due to diet-related impairment of the vascular system ${ }^{(33-35)}$. However, the acute lower salt $(0.5 \% \mathrm{NaCl})$ challenge demonstrated that much of the apparent effect of the HSFS diet on BP could be reversed by reducing its salt content to regular levels. Compared to our previous study in Yucatan miniature pigs fed a standard post-weaning diet $(0.5 \% \mathrm{NaCl})^{(12)}$, the HSFS $(4.5 \% \mathrm{NaCl})$ diet led to an increase in MAP of $12-14 \mathrm{mmHg}$. However, after $7 \mathrm{~d}$ of being on the lower-salt version of the HSFS diet $(0.5 \% \mathrm{NaCl}$ ), MAP (i.e. 118.3 (SEM 2.8) and 114.3 (SEM 1.8) $\mathrm{mmHg}$ for the IUGR and NW pigs, respectively) had decreased to values similar to those measured in pigs fed the $0.5 \% \mathrm{NaCl}$ standard diet for 9 months (i.e. MAP: 115.7 (SEM 2.9) and 110.6 (SEM 3.3) mmHg for the IUGR and NW pigs, respectively) ${ }^{(12)}$. These findings are consistent with a comprehensive study done in rats, in which the researchers separately examined the effects of dietary fat, $\mathrm{NaCl}$, sugar, and combinations of these components on systemic BP, and found that $\mathrm{NaCl}$ had the single most significant effect on $\mathrm{BP}$, followed by the fat content of the diet ${ }^{(18)}$

It should also be noted that the HSFS diet is 'dilute' in protein and this could have independent effects on BP outcomes by compromising kidney development. However, unlike studies which have demonstrated that a low-protein diet during pregnancy can result in higher BP in the offspring because of reduced nephrogenesis ${ }^{(4)}$, all animals in the present study were fed the HSFS diet only during the post-weaning stage. Because nephrogenesis is believed to be complete in late gestation in both humans and pigs ${ }^{(4)}$, the effect of the protein content of the post-weaning diet on nephrogenesis is likely to be minimal. Indeed, compared to our previous study $^{(12)}$ with a regular diet, the HSFS diet did not seem to affect nephron numbers in the IUGR pigs (296100 (SEM $28700)$ v. 250600 (SEM 28100)).

We also included an SF piglet from each litter to investigate whether pre-weaning diet (i.e. suckling $v$. formula) has an effect on risk for developing biomarkers of hypertension later in life. However, there were no differences between the NW and SF pigs for any of the parameters examined. While some studies have demonstrated that breast-feeding may lead to reductions in adolescent and adult BP values $^{(36,37)}$, others have not ${ }^{(38,39)}$. However, in Yucatan miniature pigs, it appears that prenatal nutrition, resulting in lower birth weight, is a stronger predictor of risk factors for adult CVD than pre-weaning nutrition.

In summary, lower birth weight and catch-up growth in the IUGR pigs are associated with increased adiposity, which is significantly correlated with BP. Feeding a post-weaning, Western-style diet high in sugar, salt and saturated and trans-fats exacerbated the fetally programmed DAP in the IUGR pigs ${ }^{(12)}$, resulting in diastolic hypertension. However, while nephron numbers tended to be reduced in the IUGR pigs, this did not severely affect renal function.

\section{Acknowledgements}

The present work was supported in part by operating grants to R. F. B. from the Canadian Institutes of Health Research (CIHR) and from the International Life Sciences Institute North America (ILSI-N.A.). (for further information about ILSI-N.A., call +1 2026590074 or email ilsina@ilsi.org). The opinions expressed herein are those of the authors and do not necessarily represent the views of ILSI-N.A. We thank Sophie Gagnon and Brendan Webber for laboratory assistance and Leslie McKnight for assistance with animal care. We are grateful to Dr John McLean, PhD, Memorial University of Newfoundland, for use of histology analytical system. S. B. M. helped design the overall project, conducted the animal experiment, collected and analysed the data, and wrote the manuscript. D. S. M. assisted with the animal experiment and data collection. B. N. V. V. provided guidance and assistance with the experiment and telemetry data analysis, and helped finalise the manuscript. R. F. B. originated and supervised the overall project, obtained funding, assisted with the experiment and finalised the manuscript. The authors have no conflicts of interest.

\section{References}

1. Carlstrom M, Sallstrom J, Skott O, et al. (2007) Uninephrectomy in young age or chronic salt loading causes saltsensitive hypertension in adult rats. Hypertension $\mathbf{4 9}$, 1342-1350.

2. Gamborg M, Byberg L, Rasmussen F, et al. (2007) Birth weight and systolic blood pressure in adolescence and adulthood: meta-regression analysis of sex- and age-specific results from 20 Nordic studies. Am J Epidemiol 166, $634-645$. 
3. Vickers MH, Breier BH, Cutfield WS, et al. (2000) Fetal origins of hyperphagia, obesity, and hypertension and postnatal amplification by hypercaloric nutrition. Am J Physiol Endocrinol Metab 279, E83-E87.

4. Bagby SP (2007) Maternal nutrition, low nephron number, and hypertension in later life: pathways of nutritional programming. J Nutr 137, 1066-1072.

5. Schreuder MF \& Nauta J (2007) Prenatal programming of nephron number and blood pressure. Kidney Int $\mathbf{7 2}$, 265-268.

6. Perala MM, Moltchanova E, Kaartinen NE, et al. (2011) The association between salt intake and adult systolic blood pressure is modified by birth weight. Am J Clin Nutr 93, 422-426.

7. de Boer MP, Ijzerman RG, de Jongh RT, et al. (2008) Birth weight relates to salt sensitivity of blood pressure in healthy adults. Hypertension 51, 928-932.

8. Magalhaes JC, da Silveira AB, Mota DL, et al. (2006) Renal function in juvenile rats subjected to prenatal malnutrition and chronic salt overload. Exp Physiol 91, 611-619.

9. Simonetti GD, Raio L, Surbek D, et al. (2008) Salt sensitivity of children with low birth weight. Hypertension $\mathbf{5 2}$, 625-630.

10. Langley-Evans SC \& Jackson AA (1996) Rats with hypertension induced by in utero exposure to maternal low-protein diets fail to increase blood pressure in response to a high salt intake. Ann Nutr Metab 40, 1-9.

11. Zimanyi MA, Bertram JF \& Black MJ (2004) Does a nephron deficit in rats predispose to salt-sensitive hypertension? Kidney Blood Press Res 27, 239-247.

12. Myrie SB, McKnight LL, Van Vliet BN, et al. (2011) Low birth weight is associated with reduced nephron number and increased blood pressure in adulthood in a novel spontaneous intrauterine growth-restricted model in Yucatan miniature swine. Neonatology 100, 380-386.

13. Mackenzie HS, Lawler EV \& Brenner BM (1996) Congenital oligonephropathy: the fetal flaw in essential hypertension? Kidney Int Suppl 55, S30-S34.

14. Khan IY, Dekou V, Douglas G, et al. (2005) A high-fat diet during rat pregnancy or suckling induces cardiovascular dysfunction in adult offspring. Am J Physiol Regul Integr Comp Physiol 288, R127-R133.

15. Mitra A, Alvers KM, Crump EM, et al. (2009) Effect of high-fat diet during gestation, lactation, or postweaning on physiological and behavioral indexes in borderline hypertensive rats. Am J Physiol Regul Integr Comp Physiol 296, R20-R28.

16. Amini M, Esmaillzadeh A, Shafaeizadeh S, et al. (2010) Relationship between major dietary patterns and metabolic syndrome among individuals with impaired glucose tolerance. Nutrition 26, 986-992.

17. Kant AK, Graubard BI \& Schatzkin A (2004) Dietary patterns predict mortality in a national cohort: the National Health Interview Surveys, 1987 and 1992. J Nutr 134, 1793-1799.

18. Song J, Hu X, Shi M, et al. (2004) Effects of dietary fat, $\mathrm{NaCl}$, and fructose on renal $\mathrm{Na}$ and water transporter abundances and systemic blood pressure. Am J Physiol Renal Physiol 287, F1204-F1212.

19. American Heart Association (AHA) (2008) International cardiovascular disease statistics: statistical fact sheet - populations: 2008 update. http://www.americanheart.org/downloadable/ heart/1201543457735FS06INT08.pdf (updated 2008; cited 1 February 2009).
20. Hegarty PV \& Allen CE (1978) Effect of pre-natal runting on the post-natal development of skeletal muscles in swine and rats. J Anim Sci 46, 1634-1640.

21. CDC (2004) Trends in intake of energy and macronutrients United States, 1971-2000. Morb Mortal Wkly Rep 53, 80-82.

22. Kant AK (2003) Reported consumption of low-nutrient-density foods by American children and adolescents: nutritional and health correlates, NHANES III, 1988 to 1994. Arch Pediatr Adolesc Med 157, 789-796.

23. NRC (1998) Nutrient Requirements of Swine 10th ed. Washington, DC: National Academy Press.

24. Folch J, Lees M \& Sloane Stanley GH (1956) A simple method for the isolation and purification of total lipides from animal tissues. J Biol Chem 226, 497-509.

25. Johnson KJ, Wreford NG, Hoy WE, et al. (2000) Estimating total glomerular number in human kidneys with a physical disector/fractionator combination. Image Anal Stereol 20, $105-108$

26. Swindle MM (2007) Swine in the Laboratory: Surgery, Anesthesia, Imaging, and Experimental Techniques, 2nd ed. Boca Raton, FL: CRC Press.

27. Ozanne SE \& Hales CN (2004) Lifespan: catch-up growth and obesity in male mice. Nature 427, 411-412.

28. Yiannikouris F, Gupte M, Putnam K, et al. (2010) Adipokines and blood pressure control. Curr Opin Nephrol Hypertens 19, 195-200.

29. Davy KP \& Hall JE (2004) Obesity and hypertension: two epidemics or one? Am J Physiol Regul Integr Comp Physiol 286, R803-R813.

30. Griffin KA, Kramer H \& Bidani AK (2008) Adverse renal consequences of obesity. Am J Physiol Renal Physiol 294, F685-F696.

31. Beevers G, Lip GY \& O'Brien E (2001) ABC of hypertension: the pathophysiology of hypertension. BMJ 322, 912-916.

32. Tin LL, Beevers DG \& Lip GY (2002) Systolic vs diastolic blood pressure and the burden of hypertension. J Hum Hypertens 16, 147-150.

33. Hoet JJ, Ozanne S \& Reusens B (2000) Influences of pre- and postnatal nutritional exposures on vascular/endocrine systems in animals. Environ Health Perspect 108, Suppl. 3, $563-568$

34. Martyn CN, Barker DJ, Jespersen S, et al. (1995) Growth in utero, adult blood pressure, and arterial compliance. Br Heart J 73, 116-121.

35. Martyn CN \& Greenwald SE (2001) A hypothesis about a mechanism for the programming of blood pressure and vascular disease in early life. Clin Exp Pharmacol Physiol 28, 948-951.

36. Martin RM, Ben-Shlomo Y, Gunnell D, et al. (2005) Breast feeding and cardiovascular disease risk factors, incidence, and mortality: the Caerphilly study. J Epidemiol Community Health 59, 121-129.

37. Owen CG, Whincup PH, Gilg JA, et al. (2003) Effect of breast feeding in infancy on blood pressure in later life: systematic review and meta-analysis. BMJ 327, 1189-1195.

38. Parikh NI, Hwang SJ, Ingelsson E, et al. (2009) Breastfeeding in infancy and adult cardiovascular disease risk factors. $\mathrm{Am} \mathrm{J}$ Med 122, 656-663.e1.

39. Holmes VA, Cardwell C, McKinley MC, et al. (2010) Association between breast-feeding and anthropometry and CVD risk factor status in adolescence and young adulthood: the Young Hearts Project, Northern Ireland. Public Health Nutr 13, 771-778. 